\title{
Determination of Manufacturing Process Conditions by Using MCDM Methods: Application in Laser Cutting
}

\author{
Milos Madic ${ }^{1}$, Jurgita Antucheviciene ${ }^{2}$, Miroslav Radovanovic ${ }^{1}$, Dusan Petkovic ${ }^{1}$ \\ ${ }^{1}$ University of $\mathrm{Nis}$ \\ A. Medvedeva 14, 18000 Nis, Serbia \\ E-mail.madic@masfak.ni.ac.rs,mirado@masfak.ni.ac.rs,dulep@masfak.ni.ac.rs
}

${ }^{2}$ Vilnius Gediminas Technical University

Sauletekio av. 11, LT-10223, Vilnius, Lithuania

E-mail. jurgita.antucheviciene@vgtu.lt

cross $^{\text {ref }}$ http://dx.doi.org/10.5755/j01.ee.27.2.13428

Manufacturing is a primary generator of wealth of the country and is essential for economic growth. Determination of the most suitable manufacturing process conditions for a given application is very complex task and requires consideration of a number of conflicting and diverse process performance characteristics (criteria). In this paper the application of a recent multi-criteria decision making (MCDM) method, i.e. weighted aggregated sum product assessment (WASPAS) for determination of manufacturing process conditions in laser cutting was discussed. Laser cutting experiment was conducted based on Taguchi's $L_{9}$ experimental design by varying the laser power, cutting speed, assist gas pressure and focus position at three levels. Based on obtained experimental results, a MCDM model consisting of nine alternatives and six criteria was defined. In order to determine the relative significance of considered criteria a pair-wise comparison matrix of the AHP method was used. Stability of the obtained ranking of alternatives was checked by varying values of coefficient of linear combination and by the application of operational competitiveness ratings analysis (OCRA) method.

Keywords: Multi-Criteria Decision Making, Manufacturing, Laser Cutting, WASPAS, OCRA.

\section{Introduction}

Manufacturing is purposeful human activity in which the raw materials and semi-finished products are transformed into products that meet human needs. Products are created in the manufacturing process with the decisive participation of man. Manufacturing is a primary generator of wealth of the country and is essential for economic growth. It represents the material basis for the functioning of all other social processes and activities. The basic tenet of modern manufacturing is produce as much as possible highquality products with minimum costs that accompany all manufacturing stages, from idea initiation to product realization on the market. The aim of manufacturing is to render the object of labor from a lower to a higher use value by using information, energy and work resources with the decisive participation of man. Off course, the final product must be recognized as a value in the market (Lazic et al., 2002; Radovanovic, 2002).

In the modern manufacturing and business environment manufacturers are seeking greater competitive advantage through better product design and product quality, lower costs, greater satisfaction of customers, quick response to market changes, reducing the time to introduce new products on the market, etc. At the same time ways to reduce production costs are searched. Competition on a global level requires systematic and integrated planning and optimization of all activities in the manufacturing environment. Practical problems that occur in real manufacturing environment often require formulating and solving multiple-criteria optimization problems (Madic et al., 2015a). These problems are usually solved by integrating mathematical models, created on the basis of experimental data obtained from the realized experimental research and appropriate optimization methods and algorithms. The application of the Taguchi method as well as artificial neural networks and other soft computing tools have also significant role. The main problems of the previously mentioned techniques lie in the following (Chakraborty et al., 2015): (i) determined "optimal" solution requires additional resources, i.e. process engineers might have to perform additional experimental trials in order to validate determined solution, (ii) it might happen that determined "optimal" solution cannot be realized on a given machine tool. Additionally, the application of these methods in some cases requires domain experts and considerable knowledge in mathematical modeling, artificial intelligence and optimization which may be a barrier for wider application in real manufacturing environment.

As noted by Chakraborty and Zavadskas (2014) decision makers in the manufacturing sector frequently face the problem of assessing a wide range of known alternative options and selecting the best one based on a set of conflicting criteria. In this context, the application of multicriteria decision making (MCDM) methods is essential for optimization of the overall performance of resources' utilization and means to work in the development, design, production and all other activities (Rao, 2007). The selection of manufacturing technology, machine tools, manufacturing process conditions, cutting tools, material selection for tool 
holder, machining coolant and lubrication agents, maintenance policy selection, evaluation of environmentally conscious manufacturing practices, flexible management support and so on, are only some of the examples that require the application of different MCDM methods in real and laboratory conditions (Karsak \& Ahiska, 2008; Chan \& Prakash, 2012; Ic et al., 2012; Hasan Aghdaie et al., 2013; Calışkan et al., 2013; Chatterjee \& Chakraborty, 2013; Gadakh et al., 2013; Temucin et al., 2013; Thirumalai \& Senthilkumaar, 2013; Chakraborty \& Zavadskas, 2014; Govindan et al., 2014; Hajdasz, 2014; Petkovic et al., 2015).

In this paper, application of a recent MCDM method, i.e. weighted aggregated sum product assessment (WASPAS) method for determination of manufacturing process conditions in laser cutting considering different technological, economical and quality criteria was discussed. Although it is a relatively new MCDM method, the WASPAS method was already successfully used to solve many decision making problems such as assessment of health and safety solutions at a construction site (Dejus \& Antucheviciene, 2013), improvement of daylighting in vernacular buildings (Siožinyte \& Antucheviciene, 2013), selection of the best place for shopping mall location with foresight perspective (Zolfani et al., 2013), selection and ranking of the feasible location areas of wind farms and assessing the types of wind turbines (Bagocius et al., 2014), evaluation of real-time intelligent sensors for structural health monitoring of bridges (Bitarafan et al., 2014), determination of outsourcing strategies (Lashgari et al., 2014), identification and prioritization of suitable regions for construction of expensive solar power plants (Vafaeipour et al., 2014). Unlike previous studies related to the application of the WASPAS method for solving manufacturing MCDM problems (Chakraborty \& Zavadskas, 2014; Chakraborty et al., 2015a; Chakraborty et al., 2015b), this study is based on real experimental data obtained through realization of Taguchi based experimentation of $\mathrm{CO}_{2}$ laser cutting of aluminum alloy. After the detail discussion of the main laser cutting performance characteristics (criteria), a MCDM model which can be used to select the most suitable combination of laser cutting parameter values considering main performance criteria has been defined. A pair-wise comparison matrix of the AHP method was then used to determine the relative significance of considered criteria. In the application of the WASPAS method, in order to investigate the influence of laser cutting parameters on the mean value of total relative importance of alternatives, analysis of means (ANOM) was performed. In order to validate the obtained complete rankings of alternatives obtained by the application of the WASPAS method, operational competitiveness ratings analysis (OCRA) method has also been applied.

\section{MCDM Model for Laser Cutting Performance Characteristics}

As majority of the machining processes, laser cutting process is complex multi input-multi output (MIMO) machining process in which a number of controllable parameters (inputs) have essential role on the process performance characteristics (outputs). For a given laser cutting machine, workpiece (material and thickness) and selected laser cutting method, among others, the main parameters that can be controlled during the actual laser cutting operation are laser power, cutting speed and assist gas pressure. Change of main laser cutting parameter values considerable affect laser cutting performance characteristics such as quality aspects (surface roughness, kerf width and taper, HAZ, dross), process performance (severance energy, power requirement, etc.), manufacturing cost, and productivity (such as material removal rate (MRR)) (Figure 1).

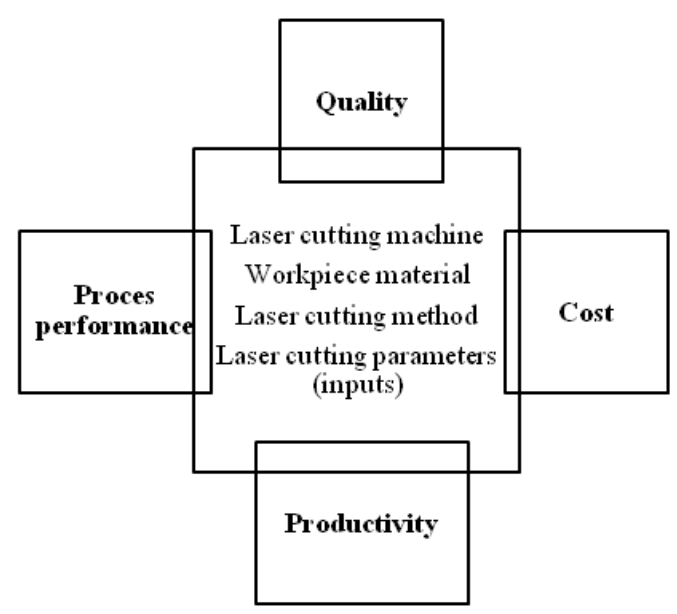

Figure 1. Laser cutting performance characteristics

The fact that changes in laser cutting parameter values differently affect laser cutting performance characteristics makes the planning and control of laser cutting process very complex and time consuming task. For example, it is clear that increase in cutting speed implies increase of MRR and obtaining a narrower kerf, however, excessive cutting speed may result in kerf taper, dross formation or even inability to obtain a full cut. Therefore careful selection of laser cutting parameter values, i.e. cutting conditions for a given application is of prime importance. Since one need to consider a number of laser cutting performance characteristics at the same time, approach based on the application of MCDM methods is justified.

Laser cutting experiment was performed in real industrial environment by using Prima Industry $\mathrm{CO}_{2}$ laser cutting machine delivering a maximum output power of 4 $\mathrm{kW}$ at a wavelength of $10.6 \mu \mathrm{m}$. The cuts were performed in a continuous wave operating mode with Gaussian distribution beam mode $\left(\mathrm{TEM}_{00}\right)$ on $3 \mathrm{~mm}$ thick aluminummagnesium alloy $\left(\mathrm{AlMg}_{3}\right)$ sheet. Nitrogen gas with a purity of $99.95 \%$ was used as assist gas. A focusing lens with a focal length of $5 \mathrm{in}$. $(127 \mathrm{~mm})$ was used to perform the cut. The conical shape nozzle with 2-mm nozzle diameter was used.

Nine experimental trials with different combination of laser cutting parameters (laser power, assist gas pressure and cutting speed) were conducted in accordance with the standard L 9 Taguchi's orthogonal array. In the present study each laser cut obtained in experimental trial is assessed regarding six criteria, three related to quality such as perpendicularity of the cut $(\mathrm{u})$, kerf width $\left(\mathrm{K}_{\mathrm{w}}\right)$ and surface roughness $\left(\mathrm{R}_{\mathrm{a}}\right)$, and three related to process, cost and productivity. Laser cut quality characteristics were measured 
by means of Surftest SJ-301 (Mitutoyo) profilometer (for measurement of surface roughness) and optical coordinate measuring device Mitutoyo (typ: QSL-200Z) (for measurement of kerf widths). Perpendicularity of the cut was calculated considering top and bottom kerf widths.

Laser cutting process performance for each experimental trial was assessed by calculating Gabzdyl's coefficient which was calculated as follows (Ion, 2005):

$$
S=\frac{v \cdot d}{K_{w} \cdot R_{a}},
$$

where: $v$ is cutting speed, $d$ is workpiece thickness, $K_{w}$ is average kerf width, and $R_{a}$ is average surface roughness.

For a given laser cutting application an increase in assist gas pressure increases variable cost since higher pressure implies higher assist gas flow. For 2-mm nozzle diameter, based on table data from literature (www.boconline.co.uk), one can derive the mathematical relationship between assist gas consumption $\left(\mathrm{Q}\right.$ in $\mathrm{m}^{3} / \mathrm{h}$ ) and assist gas pressure ( $\mathrm{p}$ in bar) in the following form:

$$
Q=\frac{55}{25} \cdot p
$$

Multiplying the assist gas consumption with the price of $\mathrm{c}=6 \mathrm{EUR} / \mathrm{m}^{3}$ of nitrogen one can easily calculate assist gas costs in $\mathrm{EUR} / \mathrm{h}(\mathrm{C})$ :

$$
C=Q \cdot c .
$$

For a given combination of laser cutting parameter values and also considering obtained kerf width productivity can be considered by calculating MRR by:

$$
M R R=v \cdot d \cdot K_{w} .
$$

It is undoubtedly clear that laser cutting performance characteristics do not have the same importance. For example, it is clear that perpendicularity of the cut, upon which the laser cuts are classified as per EN ISO standard, is more important criterion that kerf width. Laser made parts which are not perpendicular are not applicable and can be considered as waste. Therefore one needs to determine the relative importance of laser cutting performance characteristics, i.e. criteria in the context of MCDM analysis, by assigning them a certain criteria weights. In this study, based on the experience, relative importance of laser cutting performance characteristics were determined by using the geometric mean approach of the AHP method. The Saaty nine-point preference scale (Saaty, 1980) is adopted for constructing the pair-wise comparison matrix (Table 1).

Criteria weights of laser cutting performance characteristics were determined by using following equations (Madic et al., 2015a):

$$
\begin{aligned}
& \mathrm{GM}_{\mathrm{i}}=\left(\prod_{j=1}^{n} b_{i j}\right)^{1 / n} . \\
& w_{j}=\mathrm{GM}_{i} / \sum_{j=1}^{n} \mathrm{GM}_{i} .
\end{aligned}
$$

Table 1

Comparison matrix of considered criteria

\begin{tabular}{|c|c|c|c|c|c|c|}
\hline & $\mathbf{u}$ & $\mathbf{K}_{\mathbf{w}}$ & $\mathbf{R}_{\mathbf{a}}$ & $\mathbf{S}$ & $\mathbf{C}$ & MRR \\
\hline $\mathrm{u}$ & 1 & 5 & 3 & 5 & 3 & 3 \\
\hline $\mathrm{K}_{\mathrm{w}}$ & 0.2 & 1 & 0.33 & 2 & 0.33 & 0.33 \\
\hline $\mathrm{R}_{\mathrm{a}}$ & 0.33 & 3 & 1 & 5 & 3 & 3 \\
\hline $\mathrm{S}$ & 0.2 & 0.5 & 0.2 & 1 & 0.33 & 0.33 \\
\hline $\mathrm{C}$ & 0.33 & 3 & 0.33 & 3 & 1 & 1 \\
\hline $\mathrm{MRR}$ & 0.33 & 3 & 0.33 & 3 & 1 & 1 \\
\hline
\end{tabular}

Using above-mentioned equations criteria weights were obtained as $\mathrm{w}=\left[\begin{array}{llll}0.39, & 0.06,0.24, & 0.05,0.13,0.13\end{array}\right]$. Therefore, perpendicularity of the cut followed by surface roughness are criteria with the greatest importance, respectively. This is justified since quality characteristics are of prime importance for customers while manufacturers are striving to secure high quality usable parts.

Although this is subjective approach for determination of the relative importance of criteria, consistency check of determined criteria weights was performed. For six considered criteria, i.e. for random index (RI) of 1.25, consistency index $(\mathrm{CI})$ and consistency ratio $(\mathrm{CR})$ values of 0.054 and 0.043 were obtained, respectively. CI and CR values show that determination of criteria weights is reasonable.

Based on the measured and calculated laser cutting performance characteristics, the data for decision matrix were obtained (Table 2). The first three columns represent specific values of laser cutting parameters (laser power - $\mathrm{P}$, assist gas pressure $-\mathrm{p}$ and cutting speed $-\mathrm{v}$ ) which are used in experimentation. In the MCDM framework, experimental trials with specific combination of laser cutting parameters represent alternatives, whereas laser cutting performance characteristics represent criteria for assessment of alternatives, i.e. laser cuts. Here it should be noted that except MRR and S, all other criteria are minimization in nature, where lower attribute values of alternatives are preferred.

\section{Applied MCDM Methods}

In this paper, determination of decision rule for complete ranking of alternatives, i.e. laser cuts was performed by using the recently developed MCDM method, i.e. the WASPAS method. For the purpose of validation, the OCRA method was also applied.

\section{WASPAS Method}

This MCDM method was proposed by Zavadskas et al. (2012). In essence this method represents a unique combination of two well known MCDM methods, i.e. weighted sum method (WSM) and weighted product method (WPM). The total relative importance of $\mathrm{i}$-th alternative, based on weighted sum method (WSM), is calculated as follows (Chakraborty \& Zavadskas, 2014). 
Experimental trials and data for developed decision matrix

\begin{tabular}{|c|c|c|c|c|c|c|c|c|c|}
\hline Trial & $\begin{array}{c}\mathbf{P} \\
(\mathbf{k W})\end{array}$ & $\begin{array}{c}\mathbf{p} \\
\text { (bar) }\end{array}$ & $\begin{array}{c}\mathbf{v} \\
(\mathbf{m} / \mathbf{m i n})\end{array}$ & $\begin{array}{c}\mathbf{u} \\
(\mathbf{m m})\end{array}$ & $\begin{array}{c}\mathbf{K w} \\
(\mathbf{m m})\end{array}$ & $\begin{array}{c}\text { Ra } \\
(\mu \mathrm{m})\end{array}$ & $\mathbf{S}$ & $\begin{array}{c}\text { C } \\
(\text { EUR/h) }\end{array}$ & $\begin{array}{c}\text { MRR } \\
\left(\mathrm{mm}^{3} / \mathrm{min}\right)\end{array}$ \\
\hline 1 & 3 & 6 & 3 & 0.10 & 0.41 & 3.21 & 67859741.45 & 79.2 & 3719 \\
\hline 2 & 3 & 8 & 3.25 & 0.15 & 0.39 & 4.15 & 59604167.2 & 105.6 & 3843 \\
\hline 3 & 3 & 10 & 3.5 & 0.12 & 0.47 & 4.95 & 44830125.84 & 132 & 4968 \\
\hline 4 & 3.5 & 6 & 3.25 & 0.15 & 0.44 & 3.04 & 72534568.61 & 79.2 & 4311 \\
\hline 5 & 3.5 & 8 & 3.5 & 0.17 & 0.50 & 4.18 & 49840510.37 & 105.6 & 5292 \\
\hline 6 & 3.5 & 10 & 3 & 0.14 & 0.54 & 4.08 & 40976142.78 & 132 & 4845 \\
\hline 7 & 4 & 6 & 3.5 & 0.18 & 0.45 & 3.21 & 72314547.62 & 79.2 & 4750 \\
\hline 8 & 4 & 8 & 3 & 0.17 & 0.46 & 4 & 49019607.84 & 105.6 & 4131 \\
\hline 9 & 4 & 10 & 3.25 & 0.16 & 0.53 & 4.92 & 37473192.25 & 132 & 5156 \\
\hline
\end{tabular}

$$
Q_{i}^{(1)}=\sum_{j=1}^{n} \bar{x}_{i j} \cdot w_{j},
$$

where $w_{j}$ is criteria weight which represents relative importance or significance of the $j$-th criterion.

The total relative importance of $i$-th alternative, based on weighted product method (WPM), is calculated as follows:

$$
Q_{i}^{(2)}=\prod_{j=1}^{n} \bar{x}_{i j}^{w_{j}}
$$

By the WASPAS method, a more generalized equation for determining the total relative importance of alternatives is developed as below (Zavadskas et al., 2012):

$$
\begin{aligned}
& Q_{i}=\lambda \cdot \sum_{j=1}^{n} \bar{x}_{i j} \cdot w_{j}+(1-\lambda) \cdot \prod_{j=1}^{n} \bar{x}_{i j}^{w_{j}}, \\
& \lambda=0,0.1, \ldots, 1,
\end{aligned}
$$

where $\lambda$ is coefficient of linear combination and usually takes value of 0.5 . By varying values of $\lambda$ one can observe the change in values of total relative importance of alternatives as well as rankings of alternatives.

The complete ranking of alternatives is obtained considering total relative importance $\left(\mathrm{Q}_{\mathrm{i}}\right)$ values, whereas higher $\mathrm{Q}_{\mathrm{i}}$ ensures better ranking position.

For the purpose of normalization, the WASPAS method uses the following equations (Zavadskas et al., 2012):

- for maximization criteria:

$\bar{x}_{i j}=x_{i j} / \max _{i} x_{i j}$

- for minimization criteria:

$\bar{x}_{i j}=\min _{i} x_{i j} / x_{i j}$

\section{OCRA Method}

The operational competitiveness ratings analysis (OCRA) method uses an intuitive approach for incorporating the decision maker's preferences about the relative importance of the criteria (Parkan \& Wu, 1997). This method has the advantage of treating alternatives with respect to maximization and minimization criteria separately. Another major advantage of the OCRA method is that it is a nonparametric approach i.e. calculation procedure is not affected by the introduction of any additional parameters such in the case of the WASPAS method. More details about the OCRA method, computational procedure and application examples are given in (Madic et al., 2015b).

\section{Results and Discussion}

Computational details of the WASPAS method for multi-criteria analysis of laser cutting performance characteristics obtained in $\mathrm{CO}_{2}$ laser cutting of $\mathrm{AlMg}_{3}$ alloy are given in Table 3 .

Table 3

\section{Computational details of the WASPAS method (for} $\lambda=\mathbf{0 . 5})$

\begin{tabular}{|c|c|c|c|c|}
\hline Trial & $Q_{i}^{(1)}$ & $Q_{i}^{(2)}$ & $Q_{i}$ & Rank \\
\hline 1 & 0.943 & 0.937 & 0.940 & 1 \\
\hline 2 & 0.717 & 0.711 & 0.714 & 6 \\
\hline 3 & 0.740 & 0.730 & 0.735 & 4 \\
\hline 4 & 0.827 & 0.810 & 0.819 & 2 \\
\hline 5 & 0.701 & 0.688 & 0.694 & 7 \\
\hline 6 & 0.717 & 0.711 & 0.714 & 5 \\
\hline 7 & 0.787 & 0.759 & 0.773 & 3 \\
\hline 8 & 0.686 & 0.678 & 0.682 & 8 \\
\hline 9 & 0.652 & 0.642 & 0.647 & 9 \\
\hline
\end{tabular}

Based on the total relative importance values of alternatives (laser cuts), the complete ranking of the laser cuts can be derived in descending order as: 1-4-7-3-6-2-5-89. It is observed that laser cuts obtained in trial 1 is determined as the best laser cut. It is revealed that laser cut obtained in trial 4 is the second best choice, and that laser cut obtained in trial 7 is the third choice. Laser cut obtained in trial 9 is the least preferred laser cut. Analysis of obtained complete ranking and Table 2 reveals that higher ranks are ensured when using low assist gas pressure.

In order to investigate the influence of all three laser cutting parameters on the mean value of total relative importance (Q) values of alternatives analysis of means (ANOM) was performed. Since designed experiment was implemented (Taguchi's $\mathrm{L}_{9}$ ) design of experiment (DOE) mean plot was constructed for analysis (Figure 2). The plot shows change in the mean value of total relative importance when a given laser cutting parameter goes from one to another level. The slope of the line determines the power of the laser cutting parameter influence on mean value of total relative importance. 


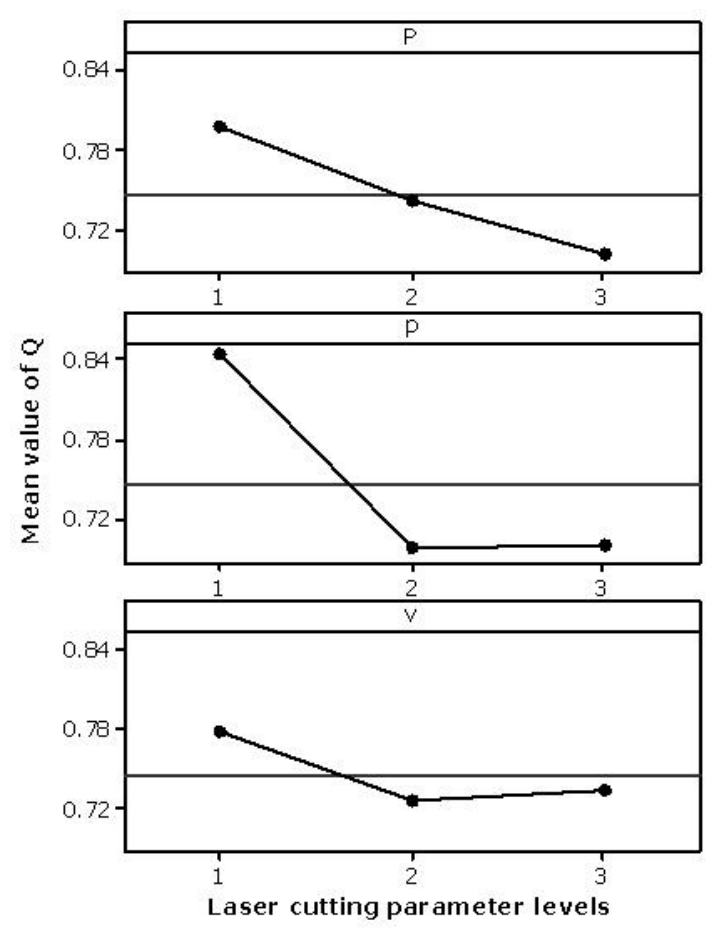

Figure 2. Effect of laser cutting parameters on mean value of $\mathrm{Q}$

The response graphs show the change in the response when a given factor goes from lower level to higher level. Graphs from Figure 2 clearly suggest a dominant influence, in a quantitative sense, of assist gas pressure on mean value of Q. Laser power has the second most significant effect on mean value of $Q$ and with an increase in laser power mean value of $Q$ decreases. The effect of cutting speed is the least pronounced.

In order to check the stability of obtained complete ranking of alternatives two validation test were performed. Firstly, the effect of varying values of coefficient of linear combination $(\lambda)$ on rankings was analyzed (Figure 3 ). Secondly, the same MCDM problem was solved by application of the OCRA method.

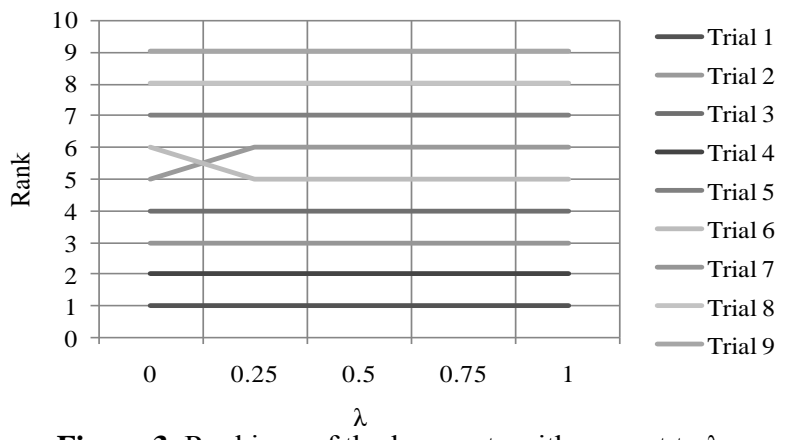

Figure 3. Rankings of the laser cuts with respect to $\lambda$

From Figure 3 it can be observed that that the obtained rankings of seven laser cuts are stable to perturbations in values of $\lambda$. On the other hand, one can notice that $\lambda=0$, i.e. when WASPAS method behaves like WPM, there are some perturbations in middle ranked alternatives (trials 2 and 5).

In order to further validate the obtained rankings of laser cuts, the OCRA method was applied. The computational details of the OCRA method and obtained complete ranking of alternatives are given in Table 4.
Table 4

Computational details of the OCRA method

\begin{tabular}{|c|c|c|c|c|}
\hline Trial & $\overline{\bar{I}}_{i}$ & $\overline{\bar{O}}_{i}$ & $P_{i}$ & Rank \\
\hline 1 & 0.514 & 0.011 & 0.525 & 1 \\
\hline 2 & 0.132 & 0.004 & 0.136 & 6 \\
\hline 3 & 0.182 & 0.024 & 0.206 & 3 \\
\hline 4 & 0.212 & 0.038 & 0.250 & 2 \\
\hline 5 & 0.029 & 0.042 & 0.070 & 7 \\
\hline 6 & 0.164 & 0.014 & 0.178 & 4 \\
\hline 7 & 0.090 & 0.053 & 0.143 & 5 \\
\hline 8 & 0.054 & 0.000 & 0.054 & 8 \\
\hline 9 & 0.000 & 0.020 & 0.020 & 9 \\
\hline$\overline{\bar{I}}_{i}$ - Linear preference rating for minimization criteria. \\
$\overline{\bar{O}}_{i}$ - Linear preference rating for maximization criteria. \\
$P_{i}$ - Overall preference ratings. \\
\hline
\end{tabular}

Analysis of Tables 3 and 4 reveals that there exists a perfect correlation between rankings obtained by WASPAS and OCRA methods with Spearman's correlation coefficient value of 0.95 . These results indicate that the determined ranking of alternatives is stable.

\section{Conclusions}

Manufacturing processes are very complex processes governed by a large number of process parameters which have adverse effect on a number of process performance characteristics. In real manufacturing environment in most cases more than one process performance characteristic have to be considered when selecting suitable manufacturing process conditions.

This paper was focused on determination of manufacturing process conditions by using MCDM methods in the application of laser technology for cutting aluminum alloy. Based on real experimental data obtained through realization of Taguchi based experimentation of $\mathrm{CO}_{2}$ laser cutting of aluminum alloy, a MCDM model is proposed to assist decision makers (production planners) in the selection of the most appropriate combination of the laser cutting parameter values. The geometric mean approach of the AHP method was used to determine the relative significance of considered criteria, and then nine realized experimental trials were assessed by applying WASPAS and OCRA methods. By the application of the ANOM it was revealed that the change in assist gas pressure has the most significant effect on the ranking of alternatives, followed by laser power and cutting speed. For the considered criteria, the application of the WASPAS and OCRA methods indicated that $\mathrm{CO}_{2}$ laser cutting of $3 \mathrm{~mm}$ thick aluminium alloy plate is to be performed by using cutting speed of $3 \mathrm{~m} / \mathrm{min}$, laser power of $3 \mathrm{~kW}$ and assist gas pressure of 6 bar.

Regarding application of the WASPAS method it was observed that this MCDM method has relatively simple computational procedure, although one need to introduce coefficient of linear combination which may have some influence on the final ranking of alternatives. As suggested by Zavadskas et al. (2012) in a cases when there exists some perturbations in rankings as determined by the application of the WASPAS method, optimal coefficient of linear 
combination can be calculated for final ranking of alternatives. In order to check the stability of obtained ranking of alternatives, decision rule was derived also by using the OCRA method. It has been observed that there exists a perfect correlation between rankings obtained by WASPAS and OCRA methods with Spearman's correlation coefficient value of 0.95 .

In relation to other approaches for determination of manufacturing process conditions, the presented MCDM approach can be relatively easily applied by process planners in real manufacturing environment. The application of MCDM methods reduce the possibility of making errors, i.e. use of inappropriate manufacturing process conditions for a given manufacturing application. Thus it may be argued that the applied MCDM methods can serve as effective decision support tool for process planners in real manufacturing environment. The development of a flexible decision support system based on the application of MCDM methods for determination of manufacturing process conditions remains an important aspect for future research.

\section{Acknowledgement}

This work was carried out within the project TR 35034 financially supported by the Ministry of Education and Science of the Republic of Serbia.

\section{References}

Bagocius, V., Zavadskas, E. K., \& Turskis, Z. (2014). Multi-person selection of the best wind turbine based on the multi-criteria integrated additive-multiplicative utility function. Journal of Civil Engineering and Management, 20(4), 590-599. http://dx.doi.org/10.3846/13923730.2014.932836.

Bitarafan, M., Zolfani, S. H., Arefi, S. L., Zavadskas, E. K., \& Mahmoudzadeh, A. (2014). Evaluation of Real-Time Intelligent Sensors for Structural Health Monitoring of Bridges Based on SWARA-WASPAS; A Case in Iran. Baltic Journal of Road and Bridge Engineering, 9(4). http://dx.doi.org/10.3846/bjrbe.2014.40

Calıskan, H., Kursuncu, B., Kurbanoglu, C., \& Guven, S. Y. (2013). Material selection for the tool holder working under hard milling conditions using different multi criteria decision making methods. Materials \& Design, 45, 473-479. http://dx.doi.org/10.1016/j.matdes.2012.09.042

Chakraborty, S., \& Zavadskas, E. K. (2014). Applications of WASPAS method in manufacturing decision making. Informatica, 25(1), 1-20. http://dx.doi.org/10.15388/informatica.2014.01

Chakraborty, S., Bhattacharyya, O., Zavadskas, E. K., \& Antucheviciene, J. (2015a). Application of WASPAS method as an optimization tool in non-traditional machining processes. Information Technology and Control, 44(1), 77-88. http://dx.doi.org/10.5755/j01.itc.44.1.7124

Chakraborty, S., Zavadskas, E. K., Antucheviciene, J. (2015b). Applications of WASPAS method as a multi-criteria decisionmaking tool. Economic Computation and Economic Cybernetics Studies and Research, 49(1), 5-22.

Chan, F. T., \& Prakash, A. (2012). Maintenance policy selection in manufacturing firms using the fuzzy MCDM approach. International Journal of Production Research, 50(23), 7044-7056. http://dx.doi.org/10.1080/00207543.2011.653451

Chatterjee, P., \& Chakraborty, S. (2012). Material selection using preferential ranking methods. Materials \& Design, 35, 384393. http://dx.doi.org/10.1016/j.matdes.2011.09.027

Dejus, T., \& Antucheviciene, J. (2013). Assessment of health and safety solutions at a construction site. Journal of Civil Engineering and Management, 19(5), 728-737. http://dx.doi.org/10.3846/13923730.2013.812578

Gadakh, V. S., Shinde, V. B., \& Khemnar, N. S. (2013). Optimization of welding process parameters using MOORA method. The International Journal of Advanced Manufacturing Technology, 69(9/12), 2031-2039. http://dx.doi.org/10. 1007/s00170-013-5188-2

Govindan, K., Kannan, D., \& Shankar, M. (2014). Evaluation of green manufacturing practices using a hybrid MCDM model combining DANP with PROMETHEE. International Journal of Production Research, 53(21), 6344-6371. http://dx.doi.org/10.1080/00207543.2014.898865

Hajdasz, M. (2014). Flexible management of repetitive construction processes by an intelligent support system. Expert Systems with Applications, 41(4), 962-973. http://dx.doi.org/10.1016/j.eswa.2013.06.063

Hasan Aghdaie, M., Hashemkhani Zolfani, S., \& Zavadskas, E. K. (2013). Decision making in machine tool selection: An integrated approach with SWARA and COPRAS-G methods. Inzinerine Ekonomika-Engineering Economics, 24(1), 517. http://dx.doi.org/10.5755/j01.ee.24.1.2822

Ic, Y. T., Yurdakul, M., \& Eraslan, E. (2012). Development of a component-based machining centre selection model using AHP. International Journal of Production Research, 50(22), 6489-6498. http://dx.doi.org/10.1080/00207543.2011.653011

Ion, J. (2005). Laser processing of engineering materials, Butterworth-Heinemann. http://dx.doi.org/10.1016/b978-0750660792/50004-0

Karsak, E. E., \& Ahiska, S. S. (2008). Improved common weight MCDM model for technology selection. International Journal of Production Research, 46(24), 6933-6944. http://dx.doi.org/10.1080/00207540701419364 
Lashgari, S., Antucheviciene, J., Delavari, A., \& Kheirkhah, O. (2014). Using QSPM and WASPAS methods for determining outsourcing strategies. Journal of Business Economics and Management, 15(4), 729-743. http://dx.doi.org/10.3846/ 16111699.2014.908789

Lazic, M., Nedic, B., \& Mitrovic, S. (2002). Tehnologija obrade metala - izbor režima obrade. Masinski fakultet Kragujevac.

Madic, M., Nedic, B., \& Radovanovic, M. (2015a). Business and engineering decision making by using multi-criteria decision making methods. University of Kragujevac.

Madic, M., Petkovic, D., \& Radovanovic, M. (2015b). Selection of non-conventional machining processes using the OCRA method. Serbian Journal of Management, 10(1), 61-73. http://dx.doi.org/10.5937/sjm10-6802

Parkan, C., \&, Wu, M.L. (1997). On the equivalence of operational performance measurement and multiple attribute decision making. International Journal of Production Research, 35(11), 2963-2988. http://dx.doi.org/10.1080/002075497194246

Petkovic, D., Madic, M., \& Radenkovic, G. (2015). Selection of the most suitable non-conventional machining processes for ceramics machining by using MCDMs. Science of Sintering, 47(2), 229-235. http://dx.doi.org/10.5937/sjm10-6802

Radovanovic, M. (2002). Tehnologija masinogradnje, Masinski fakultet Nis.

Rao, V. R. (2007). Decision making in the manufacturing environment: using graph theory and fuzzy multiple attribute decision making methods. Springer-Verlag. http://dx.doi.org/10.1007/978-1-4471-4375-8

Saaty, T. L. (1980). The analytic hierarchy process. McGraw-Hill. http://dx.doi.org/10.1080/00137918308956077

Siozinyte, E., \& Antucheviciene, J. (2013). Solving the problems of daylighting and tradition continuity in a reconstructed vernacular building. Journal of Civil Engineering and Management, 19(6), 873-882. http://dx.doi.org/10.3846/ 13923730.2013 .851113

Temucin, T., Tozan, H., Valicek, J., \& Harnicarova, M. (2013). A fuzzy based decision support model for non-traditional machining process selection. Technical Gazette, 20(5), 787-793.

Thirumalai, R., \& Senthilkumaar, J. S. (2013). Multi-criteria decision making in the selection of machining parameters for Inconel 718. Journal of Mechanical Science and Technology, 27(4), 1109-1116. http://dx.doi.org/10.1007/s12206-0130215-7

Vafaeipour, M., Zolfani, S. H., Varzandeh, M. H. M., Derakhti, A., \& Eshkalag, M. K. (2014). Assessment of regions priority for implementation of solar projects in Iran: New application of a hybrid multi-criteria decision making approach. Energy Conversion and Management, 86, 653-663. http://dx.doi.org/10.1016/j.enconman.2014.05.083

www.boconline.co.uk

Zavadskas, E. K., Turskis, Z., Antucheviciene, J., \& Zakarevicius, A. (2012). Optimization of weighted aggregated sum product assessment. Electronics and Electrical Engineering = Elektronika ir Elektrotechnika, 122(6), 3-6. http://dx.doi.org/10. 5755/j01.eee.122.6.1810

Zolfani, S. H., Aghdaie, M. H., Derakhti, A., Zavadskas, E. K., \& Varzandeh, M. H. M. (2013). Decision making on business issues with foresight perspective; an application of new hybrid MCDM model in shopping mall locating. Expert Systems with Applications, 40(17), 7111-7121. http://dx.doi.org/10.1016/j.eswa.2013.06.040

The article has been reviewed. Received in October, 2015; accepted in April, 2016. 